have been too freely transposed to the case of man; for nutritionists are often poor pathologists and worse ophthalmologists. This present volume, however, is written out of a wide personal experience of the problems involved, with an open but yet critically scientific mind, and it is certainly worth study.

\title{
NOTES
}

\section{Ophthalmological Society of the United Kingdom Annual Congress, 1964}

The Annual Congress of the Ophthalmological Society will be held at the Royal College of Physicians, Kildare Street, Dublin, from April 15 to 17, 1964.

The Bowman Lecture will be delivered by the Right Honourable the Lord Cohen of Birkenhead.

Members wishing to read a paper, to give a pictorial demonstration, or to show a film are asked to send the title, together with an abstract, to Mr. I. M. Duguid at the London Hospital, E.1., not later than November 30, 1963.

\section{Contact Lens Society \\ International Congress, 1964}

The congress will be held at Bath, Somerset, England, from May 25 to 29, 1964. Further papers are invited and intending contributors should send full details to the Secretary, Contact Lens Society, 128 Blackfriars Rd., London, S.E.1, not later than November 7, 1963.

\section{Royal Eye Hospital \\ Refresher Course, 1964}

A further course will be held at the Courage Laboratory from February 17 to $21,1964$. Those wishing to attend should apply to Prof. A. Sorsby, Courage Laboratory, Royal Eye Hospital, London, S.E.1., before December 1, 1963.

\section{OBITUARY}

\section{DAVID WILSON, 1881-1962}

Dr. David Wilson, a well-known ophthalmic surgeon in South Devon, died in Torquay after a short illness on June 5. He was 82. He was born in 1881 at Huddersfield and was educated at Epsom College. He won the Watts prize and entered St. Thomas's Hospital in 1901, where he qualified with the Conjoint diploma in 1905, taking the M.B., B.S. in 1907. In 1914 he joined the R.A.M.C. and served from 1914 to 1918, during which time he was mentioned in dispatches.

After the war he came back to Huddersfield and started to study ophthalmology, being later appointed aural and ophthalmic surgeon at the Huddersfield Royal Infirmary. In 1923 he went to Torquay. He was appointed ophthalmic surgeon to the Old Torbay Hospital, and later to the New Torbay Hospital, and was attached as ophthalmic surgeon to Paignton and Newton Abbot Hospitals. He retired in 1946. A member of the B.M.A. for 55 years, he served as honorary secretary of the Huddersfield Division in 1922-3 and as a member of the Ophthalmic Group Committee during 1938-49.

\section{CORRIGENDUM}

In the article by K. E. Schirmer, which appeared in the August issue, entititled "Assessment of Corneal Sensitivity", on p. 492, line 7, for 'hyperaesthesia' read 'hypaesthesia'. i.e. decreased sensitivity. 